\title{
MARTA ALBERT: ¿QUÉ ES HOY UN EMBRIÓN HUMANO -NO PATENTABLE-? LA DOCTRINA BRÜSTLE, CINCO AÑOS DESPUÉS ${ }^{1}$
}

\section{WHAT IS A HUMAN EMBRYO -NON-PATENTABLE- TODAY? THE BRÜSTLE DOCTRINE, FIVE YEARS LATER}

RESUMEN: El artículo lleva a cabo una revisión de la doctrina Brüstle, analizando su impacto en diversos ámbitos: el de las decisiones de la Comisión y el Parlamento europeo, especialmente en lo que respecta a la financiación de la investigación en el marco de H2020; el del propio Bundesgerichtshof y su solución al caso Brüstle; el de la Oficina Europea de Patentes, en sus decisiones posteriores sobre la patente europea solicitada por Brüstle (teniendo en cuenta el nuevo escenario que supone la patente unitaria) y, por último, en relación con la propia jurisprudencia posterior de TJUE (asunto ISCO). Este análisis nos permite afirmar que la doctrina Brüstle continua planteando interrogantes en cuanto al estatuto jurídico del embrión humano. Se apunta, en particular, la necesidad de aclarar el régimen de los embriones supernumerarios no viables.

ABSTRACT: The article is a revision of Brüstle's doctrine. Its impact on different fields is analysed: the decisions of the European Commission and the European Parliament (whit special regard to research within the framework of H2020); the final decision of Brüstle case at the German Federal Court of Justice; the European Patent Office and its final decision on Brüstle european patent and, finally, the ECJ case law post-Brüstle (ISCO v. Comptroller, 2014). This analysis allows us to affirm that there are still some remaining questions about the legal status of human embryo. The need for clearing up the status of non-viable embryos is highlighted.

PALABRAS CLAVE: Embrión humano, Dignidad, Investigación, Células madre, totipotencialidad, viabilidad.

KEYWORDS: Human embryo, dignity, research, stem cells, totipotenciality, viability

\section{INTRODUCCIÓN: ¿QUEDA ALGO POR DECIR EN EL ASUNTO BRÜSTLE?}

La sentencia del Tribunal de Justicia de la Unión Europea (TJUE) en el asunto Brüstle c. Greenpeace $(2011)^{2}$ prescribió, para el ámbito de las patentes, un nuevo

\footnotetext{
${ }^{1}$ Profesora Titular de Filosofía del Derecho. Universidad Rey Juan Carlos de Madrid.

${ }^{2}$ Sentencia del Tribunal de Justicia (Gran Sala) de 18 de octubre de 2011 (petición de decisión prejudicial planteada por Bundesgerichtshof, Alemania) Oliver Brüstle/Greenpeace eV (Asunto C-34/10), DOCE (Diario Oficial de la Unión Europea) C-362/5, 10.12.2011, en adelante, STJUE C-34/10. Texto completo disponible en español en la página web del Tribunal de Justicia de Luxemburgo,vid.,http://eurlex.europa.eu/LexUriServ/LexUriServ.do?uri=OJ\%3AC\%3A2011\%3A362\%3A000 5\%3A0006\%3Aes\%3APDF [Consulta: 13/11/2016]
} 
concepto de embrión que, en su día, abrió un intenso debate académico en el ámbito europeo (y no sólo) en torno a la investigación con células madre de origen embrionario humano ${ }^{3}$. Tanto es así que, cuando, tres años más tarde, la Corte se pronunció de nuevo sobre el sentido de la expresión "embrión humano" en la Directiva europea de patentes (asunto ISCO), el debate sobre Brüstle aún no se había cerrado.

Pocos meses antes de esta segunda sentencia, en mayo de 2014, la Comisión Barroso "vetaba" la iniciativa ciudadana "One of us", que pretendía llevar a sus últimas consecuencias la doctrina Brüstle dentro del ámbito competencial de la UE. En diciembre de 2013 se había aprobado el programa de financiación de la investigación a nivel europeo, H2020, sin que la nueva definición de embrión europeo (a efectos de patentes) produjera impacto alguno en la política de inversión europea.

Pero desde el último pronunciamiento del TJUE sobre el tema, en diciembre de 2014, parecía que Brüstle podía considerarse "caso cerrado". No creo que sea así. Basta tener presente la historia misma de la patente Brüstle para pensar que aún debe de haber cuestiones abiertas en torno a la definición de embrión y su aplicación en el ámbito de las patentes: el Bundesgerichtshof resolvió admitir la patente de Brüstle en 2012, a pesar de que la amplitud con la que el TJUE definió la expresión "embrión humano" invitaba a pensar que la solicitud devendría inviable. Un año más tarde, en cambio, la Oficina Europea de Patentes (OEP) revocaba la patente, revocación que ha confirmado mediante resolución de febrero de 2015 . El asunto está pendiente aún del resultado de la vista oral que tendrá lugar el 19 de diciembre.

\section{LA DOCTRINA BRÜSTLE: ¿QUÉ ES UN EMBRIÓN HUMANO?}

El neurobiólogo Olivier Brüstle había obtenido una patente referida a células progenitoras neuronales aisladas y depuradas, a su procedimiento de producción a partir de células madre embrionarias y a su utilización en la terapia de enfermedades neurológicas. Esta concesión fue recurrida por Greenpeace, que entendía que tanto la normativa alemana ${ }^{4}$ como la propia Directiva Europea de patentes ${ }^{5}$ impedían la concesión, pues ambos textos consideran no patentables las invenciones que tengan por objeto embriones humanos.

\footnotetext{
${ }^{3}$ De hecho, sólo la publicación de las Conclusiones del Abogado General Ives Bot ya tuvo un gran impacto en la comunidad científica. El 28 de abril de 2011 se publicó en Nature una "carta abierta" alertando sobre los inconvenientes que se derivarían de una hipotética prohibición de patentar procesos o invenciones obtenidas mediante la manipulación de células madres embrionarias" SMITH, A., 'No' to ban on stem-cell patents", Nature, 472, p. 418 (28 April 2011). Nature se hizo eco de la noticia desde el inicio, vid., ABBOTT, A., Nature 471, p. 280 (2011) "Europe rules against stem-cell patents", 16 de marzo de 2011. En respuesta a esta "carta abierta", David Albert Jones publicó (también en Nature) un artículo titulado "More at stake in stem-cell patents" (JONES, D. A., Nature 474, p. 579 (30 June 2011), donde se hacía ver que lo que estaba en juego en el caso Brüstle era mucho más que los intereses económicos de Europa. Muy crítico con esta última postura, DENOON, A., "Brüstle v. Greenpeace: implications for stem cell research", en Intellectual Property, Regenerative Medicin (2011) 6, pp. 85-87.

4 Bundesgesetz über die Erfindungspatente (25-06-1954); Gesetz zum Schutz von Embryonen (Embryonenschutzgesetz) (13-12-1990); Gesetz zur Sicherstellung des Embryonenschutzes im Zusammenhang mit Einfuhr und Verwendung menschlicher embryonaler Stammzellen, (28-06-2002).

${ }^{5}$ Directiva 98/44/CE del Parlamento Europeo y del Consejo, de 6 de julio de 1998 relativa a la protección jurídica de las invenciones biotecnológicas, Diario Oficial nL 213 de 30/07/1998, pp. 0013-0021.
} 
El asunto llega al Bundesgerichtshof, que estima necesario elevar al TJUE cuestión prejudicial para que aclare el sentido de la expresión "embrión humano" en la Directiva.

En concreto, el Bundesgerichtshof solicita que se determine qué es un embrión humano (y si lo son los embriones clónicos y los partenogénicos, y qué consideración merecen las células obtenidas de un embrión en estadio de blastocisto) y si pueden patentarse las invenciones o procedimientos que impliquen la destrucción de embriones, aunque esto último no forme parte de la información técnica de la patente ${ }^{6}$.

La sentencia del TJUE, en respuesta a la petición planteada, establece que un embrión humano es: "todo óvulo humano a partir del estadio de la fecundación"; "todo óvulo humano no fecundado en el que se haya implantado el núcleo de una célula humana madura" y, por último, "todo óvulo humano no fecundado estimulado para dividirse y desarrollarse mediante partenogénesis"”.

Por lo que se refiere a las células madre obtenidas a partir de un embrión humano en el estadio de blastocisto, el TJUE afirma que corresponde al juez nacional determinar, a la luz de los avances de la ciencia, si son aptas para iniciar el proceso de desarrollo de un ser humano, en cuyo caso quedarían incluidas en el concepto de "embrión humano".

No obstante, hay que tener presente que si la obtención de estas células conlleva la destrucción del embrión del que se extraen, el procedimiento tampoco sería patentable, por implicar la muerte del embrión, ya que la respuesta a la última cuestión es negativa: no son patentables ni las invenciones ni los procedimientos que impliquen destrucción de embriones.

EI TJUE parte de la exclusión de patentabilidad que establece la Directiva 98/44 en su artículo 6: "las invenciones cuya explotación comercial sea contraria al orden público o a la moralidad" y, entre ellas, los "procedimientos de clonación de seres humanos, los procedimientos de modificación de la identidad genética germinal del ser humano, la utilización de embriones con fines industriales o comerciales".

El fundamento de estas exclusiones se hace explícito en el Considerando 16, que nos remite a la dignidad e integridad de las personas como perspectiva desde la que se ha de ejercer el derecho de patentes.

\footnotetext{
6 «1) ¿Qué debe entenderse por "embriones humanos" del art. 6, apartado 2, letra c), de la Directiva 98/44/CE? a) ¿Están comprendidos todos los estadios de desarrollo de la vida humana desde la fecundación del óvulo o deben cumplirse requisitos adicionales, como por ejemplo alcanzar un determinado estadio de desarrollo? b) ¿Están comprendidos también los siguientes organismos: 1. óvulos humanos no fecundados a los que ha sido trasplantado el núcleo de una célula humana madura; 2. óvulos humanos no fecundados que han sido estimulados mediante partenogénesis para que se dividan y sigan desarrollándose?
}

c) ¿Están comprendidas también las células madre obtenidas a partir de embriones humanos en el estadio de blastocisto? (...)

3) ¿Está excluida de la patentabilidad, con arreglo al art. 6, apartado 2, letra c), de la Directiva, una información técnica también cuando la utilización de embriones humanos no constituye en sí la información técnica reivindicada con la patente, sino un requisito necesario para la aplicación de esa información:

a) porque la patente se refiere a un producto cuya elaboración exige la previa destrucción de embriones humanos, b) o porque la patente se refiere a un procedimiento para el que es necesario dicho producto como materia prima?»

${ }^{7}$ Vid., STJUE C-34/10, parágrafo 38.

${ }^{8}$ Ibid., parágrafo 37. 
Desde estas coordenadas, el fallo del TJUE se fundamenta en la noción de dignidad del ser humano (cuyo respeto exige, a juicio de TJUE, una noción "amplia" de embrión $^{9}$ ). En las Conclusiones del Abogado General Bot ${ }^{10}$ esa noción de dignidad se vincula no tanto a la vida humana (de imposible definición) como al cuerpo humano ${ }^{11}$. Y la clave radica en la totipotencialidad: habrá cuerpo humano en la medida en que haya una célula totipotente, puesto que hay un claro consenso en los países europeos acerca del hecho de que estas células pueden generar un ser humano completo ${ }^{12}$. No obstante, la sentencia no alude expresamente al concepto de totipotencia, sino que señala que los tipos de embrión que se relacionan en ella (fecundados, clónicos y partenogénicos) son todos, a juicio del TJUE, "aptos para iniciar el proceso de desarrollo de un ser humano"13.

\section{LA INICIATIVA CIUDADANA “ONE OF US" Y LA DISCUSIÓN PARLAMENTARIA DEL PROGRAMA HORIZON 2020}

Uno de los primeros efectos significativos de la doctrina Brüstle fue la promoción de una iniciativa legislativa ciudadana ${ }^{14}$ : "One of Us". La iniciativa consiguió reunir las firmas preceptivas (casi dos millones de ciudadanos europeos distribuidos por todos los países de la UE) y ser admitida a trámite ante la Comisión ${ }^{15}$. Perseguía el reconocimiento del

\footnotetext{
9 "El contexto y la finalidad de la Directiva revelan así que el legislador de la Unión quiso excluir toda posibilidad de patentabilidad en tanto pudiera afectar al debido respeto de la dignidad humana. De ello resulta que el concepto de «embrión humano» recogido en el artículo 6, apartado 2, letra c), de la Directiva debe entenderse en un sentido amplio", STJUE, C-34/10, parágrafo 34. Vid., Sobre el papel de la idea de dignidad, SERRANO RUIZ-CALDERÓN, JM., Dignidad versus patentabilidad (Comentario de la STJ 18 de octubre de 2011 en el asunto Brüstle/ Greenpeace), en LA LEY, No 7766, Sección Tribuna, 30 Dic. 2011, Año XXXII.

10 "Conclusiones", del Abogado General, Ives Bot, de 10 de marzo de 2011, el texto completo disponible en http://curia.europa.eu/juris/document/document.jsfdocid=134521\&mode=Ist\&pagelndex=1\&dir=\&occ=first\&p art $=1$ \&text=\&doclang=ES\&cid $=16557$ [Consulta: $13 / 11 / 2016$ ]

${ }^{11}$ Esta opción queda definida en las "Conclusiones" del Abogado General, Bot: "¿Qué debe definirse? ¿La aparición de la vida? ¿El instante asombroso que, in utero, verá cómo aquello que, no siendo quizá más que un conjunto de células, cambia de naturaleza y se convierte, ciertamente todavía no en un ser humano, pero ya en un objeto de Derecho, incluso en un sujeto de Derecho? De ningún modo", parágrafo 72.
}

12 "Conclusiones" de I. Bot, cit., parágrafo 84. Para una clara definición de "totipotencia" en relación al asunto que nos ocupa, vid., LACADENA, JR., "Sentencia del Tribunal de Justicia de la Unión Europea sobre las patentes de células troncales embrionarias. A propósito de un informe jurídico sobre patentes: El concepto y dignidad del embrión humano", en Revista de Derecho y Genoma Humano, 35:pp.145-180 (2011).

${ }^{13}$ STJUE C-34/10, parágrafos 35-36.

${ }^{14}$ El régimen jurídico de la iniciativa ciudadana se encuentra en el Reglamento (UE) № 211/2011 del Parlamento Europeo y del Consejo, de 16 de febrero de 2011 sobre la iniciativa ciudadana, DOCE L 65/1, de 11-03-2011. Disponible en http://eur-lex.europa. eu/LexUriServ/LexUriServ.do?uri=OJ:L:2011:065:0001:0022:ES:PD [Consulta: 13/11/2016].

${ }^{15}$ Es importante subrayar que hasta la fecha han prosperado sólo tres iniciativas ciudadanas a nivel europeo (http://ec.europa.eu/citizens-initiative/public/initiatives/successful), veinte han sido denegadas (no han llegado a registrarse (http://ec.europa.eu/citizens-initiative/public/initiatives/non-registered) y trece han sido retiradas (http://ec.europa.eu/citizens-initiative/public/initiatives/obsolete), lo que implica que One of Us es una de las tres que iniciativas que han llegado a la Comisión frente a las treinta y tres que no lo han conseguido [Consulta: 13/11/2016]. 
embrión humano como "uno de nosotros"16, haciendo valer, en virtud del principio de coherencia, la concepción amplia de embrión humano acuñada en Brüstle en todos los ámbitos de competencia de la Unión en los que pudiera entrar en juego la noción de "embrión": el presupuesto de la UE, la investigación y la cooperación al desarrollo ${ }^{17}$. Nos interesa fundamentalmente la segunda. La iniciativa proponía una enmienda al entonces Proyecto de Reglamento para Horizon 2020 (H2020), en la que se modificaba el artículo 16 , prohibiendo la financiación de la investigación no patentable ex Brüstle ${ }^{18}$.

"One of Us" fue presentada ante la Comisión el 28 de febrero de 2014, que respondió mediante comunicación de 28 de mayo del mismo año, "vetando" la iniciativa, esto es, no considerando oportuna su discusión en el Parlamento. El Reglamento para H2020 se había aprobado meses atrás, en diciembre, permitiendo la financiación de aquellas investigaciones que, de acuerdo con Brüstle, no podrían obtener patente en los países de la UE. La Comisión defiende el paquete H2O2O afirmando su relación de continuidad con el $7^{\circ}$ Programa Marco, su idoneidad con los informes del European Group on Bioethics $(\mathrm{EGE})^{19}$ y el apoyo ciudadano a este tipo de investigación que se deducía del último Eurobarómetro ${ }^{20}$. Sobre todo, hace referencia al sistema de "triple cerrojo" propuesto por el EGE, donde se encuentran las principales garantías para una investigación conforme al respeto debido a la dignidad humana: respeto a las legislaciones nacionales, evaluación científica y ética de cada proyecto y prohibición de financiación de aquellas investigaciones que supongan obtención de nuevas líneas de células madre, o "que impliquen la destrucción de embriones, incluida la obtención de células madre" ${ }^{21}$. Sin embargo, el artículo 19.4 del Reglamento para H2020 permite la

\footnotetext{
${ }^{16}$ La iniciativa legislativa toma su nombre de manera literal del Informe del Comité italiano de Bioética sobre Identidad y Estatuto del Embrión Humano "Identit e Statuto dell'Embrione Umano", de 27 de junio de 1996. Puede encontrarse el texto íntegro en Medicina e Morale, 1997/2, pp. 328-359.
}

${ }^{17}$ En cuanto a la necesidad de hacer valer esta concepción "amplia" de embrión en el derecho de la UE, vid., CASINI, C., CASINI, M., SPAGNOLO, A., "La sentenza della Corte di giustizia dell'Unione europea del 18 ottobre 2011 e la nozione di embrione in senso ampio", en Medicina e Morale, 2011-5, pp. 777-802.

${ }^{18}$ Literalmente: "No se financian los siguientes ámbitos de investigación: (a) actividades de investigación finalizadas por la clonación humana; (b) actividades de investigación dirigidas a modificar el patrimonio genético de los seres humanos susceptible de volver hereditarias tales modificaciones; (c) actividades de investigación dirigidas a crear embriones humanos solo para finalidades de investigación o para el aprovisionamiento de células estaminales, también mediante la transferencia de núcleos de células somáticas. (d) actividades de investigación que destruyan embriones humanos, incluso las destinadas a la obtención de células estaminales, y actividades de investigación que comporten la utilización de células estaminales embrionarias humanas en pasajes sucesivos a su obtención".

${ }^{19}$ La Directiva encarga al EGE la evaluación de los aspectos éticos vinculados a la biotecnología., vid., Directiva 44/98, cit., art. 7. Un análisis de la doctrina del EGE en torno a la experimentación con embriones humanos puede verse en ALBERT, M., "El caso Brüstle v. Greepeace y el final de la discriminación de los embriones preimplantatorios", Cuadernos de Bioética, XXIV 2013/3a a, pp. 482-484. También se hace referencia en ese trabajo a la doctrina en la materia del Tribunal Europeo de Derechos Humanos (sentencias Vo c. Francia -08-07-2004- y Evans c. Reino Unido -10-04-2007-, fundamentalmente). Hay que tener muy presente que en ellas el Tribunal no está respondiendo a la pregunta de qué es un embrión humano, sino a la pregunta de si un embrión humano puede ser considerado persona a los efectos del artículo 2 de la Convención, es decir, si puede ser titular de derechos y, en particular, del derecho a la vida, cuestión esta, desde mi punto de vista, completamente distinta de la que nos ocupa aquí. De hecho, en la sentencia Vo el Tribunal expresamente se refiere a los riesgos que para el embrión se generan de los avances de la biotecnología y a la necesidad de que el derecho le otorgue protección jurídica para evitarlos (nos referimos a ello más adelante).

${ }^{20}$ Comisión, COM(2014) 355 final, Comunicación sobre la iniciativa legislativa ciudadana "Uno de nosotros", http://ec.europa.eu/transparency/regdoc/rep/1/2014/ES/1-2014-355-ES-F1-1.Pdf [Consulta: 13/11/2016]

${ }^{21}$ Comisión, Comunicación, cit., p. 7. 
financiación de la "investigación con células madre humanas, tanto adultas como embrionarias, dependiendo tanto del contenido de la propuesta científica como del marco jurídico de los Estados miembros interesados", y esto, a pesar de que la obtención de células madre de origen embrionario pueda significar la destrucción del embrión.

Por esta razón, el informe del Comité de Asuntos Jurídicos instaba la modificación de este punto, exigiendo una prohibición explícita de financiación de toda investigación que implique la destrucción de embriones, siguiendo, además, la línea establecida ya en el contexto del Séptimo programa marco ${ }^{22}$. La Comisión desechó la enmienda.

Más tarde, desde el Parlamento, se elevaron sendas cuestiones escritas a la Comisión en la misma línea de lo solicitado por "One of us", y basadas no tanto en una motivación ética como en la preocupación por la financiación de actividades consideradas ilegales en algunos países de la Unión y por el retorno de la inversión realizada en este tipo de investigación, dado que sus resultados no podrían ser objeto de patente en Europa $^{23}$. La Comisión entendió que el hecho de que H2020 solo financiase investigación legal en el país donde se pretenda desarrollar era motivación suficiente para justificar H2020, y que este no entraba en conflicto con Brüstle, ya que la sentencia no prohibía la realización de este tipo de investigación ${ }^{24}$.

La europarlamentaria Anna Záborská (PPE) demandó en 2013 que se explicara qué medidas ha tomado la Comisión para implementar la doctrina del caso C-34/10 en relación a la protección del embrión humano en todas las áreas de políticas públicas competencia de la Unión (incluido, obviamente, H2020) ${ }^{25}$. La respuesta de la Comisión establece que se ha constituido un grupo de expertos para llevar a cabo un seguimiento de la aplicación de Brüstle en los Estados miembros, y que la dignidad del hombre, vehiculizada a través del respeto a la Carta de Derechos Fundamentales de la UE es respetada en toda actividad de la Unión ${ }^{26}$.

A pesar del veto de la Comisión, la inciativa "one of us" sigue activa. La decisión de la Comisión de no transmitir la petición al Parlamento fue recurrida, por considerarse que

\footnotetext{
${ }^{22}$ Por tanto, esa continuidad a la que se refiere la Comisión en su Comunicación de respuesta a One uf Us no es pacífica en ningún sentido. El texto literal de la petición de Enmienda 3 de la Comisión de Asuntos Legales afirma: There are considerable differences between national laws on research using human embryos and human embryonic stem cells. Union policy should not seek to harmonise national legislation. In connection with the Seventh Framework Programme, the Commission declared that it would 'continue with the current practice and [would] not submit to the Regulatory Committee proposals for projects which include research activities which destroy human embryos, including for the procurement of stem cells (Point 12 of the Commission statement re Article 6, annexed to Decision No 1982/2006/EC of the European Parliament and of the Council of 18 December 2006 concerning the Seventh Framework Programme of the European Community for research, technological development and demonstration activities (2007-2013) (OJ L 412, $30.12 .2006, p$. 1). This commitment should be inserted into this Regulation in order to ensure legal certainty. The Commission should actively support research aimed at developing alternatives to embryonic stem cells.

${ }^{23}$ Pregunta escrita de los eurodiputados Miroslav Mikolášik (PPE), Konrad Szymanski (ECR) y Radvil Morkünaitè-Mikulènienè (PPE) Referencia E-005528/2012. Disponible en inglés en http://www.europarl.europa.eu/sides/getDoc.do?pubRef=\%2f\%2fEP\%2f\%2fTEXT\%2bWQ\%2bE-2012005528\%2b0\%2bDOC\%2bXML\%2bV0\%2f\%2fEN\&language=EN, [Consulta: 13/11/2016].

${ }^{24}$ Responde en nombre de la Comisión Ms Geoghegan-Quinn, 9 agosto 2012, Ibid. 001923\%2b0\%2bDOC \%2bXML\%2bV0\%2f\%2fEN\&language=EN, [Consulta: 10/11/2016].
}

26 http://www.europarl.europa.eu/sides/getAllAnswers.do?reference=E-2013-001923\&language=EN [Consulta: 10/11/2016] 
la "Comunicación" resulta infundada, y que la Comisión no ha cumplido su obligación de deslindar en ella las razones políticas de las jurídicas que justificarían su no tramitación parlamentaria. Está pendiente de resolución ante el Tribunal General ${ }^{27}$.

\section{EL FINAL DEL CASO BRÜSTLE: LA CONCESIÓN DE LA PATENTE ALEMANA (BGH, 2012) Y LA DENEGACIÓN DE LA PATENTE EUROPEA (Asunto Geron v. Brüstle, OEP, 2015)}

La decisión del TJUE fue trasladada al órgano jurisdiccional que la había solicitado y que debía aplicar el nuevo concepto de embrión humano a la solución del conflicto entre Olivier Brüstle y Greenpeace. La sentencia del Bundesgerichtshof de 27 de noviembre de $2012^{28}$ estimó la patente solicitada conforme a derecho (atendiendo a la petición subsidiaria formulada por Brüstle, que añadía la fórmula "sin destrucción de embriones").

En puridad, la razón por la que se entiende atendible la petición de Brüstle no radica en que el proceso cuya patentabilidad es objeto de la contienda permitiera la extracción de células pluripotentes sin destrucción del embrión, sino en que emplea "embriones" que no son embriones y por tanto, su destrucción no equivale a la destrucción de un embrión: se trata de los embriones supernumerarios (sobrantes de procesos de fecundación humana asistida y cedidos para su empleo en investigación científica) no viables, que, no entrarían dentro del concepto de "embrión" de la doctrina Brüstle, ya que no tienen capacidad de desarrollarse hasta constituir un ser humano ${ }^{29}$.

Como es fácil advertir, la controversia se centra en torno a la interpretación de cuándo un embrión es "apto para iniciar el proceso de desarrollo de un ser humano", criterio establecido por la sentencia del TJUE para fijar el concepto de embrión.

${ }^{27}$ Recurso ante el Tribunal General interpuesto el 25 de julio de 2014 «Uno de nosotros»y otros/Parlamento
y $\quad$ otros, (Asunto http://curia.europa.eu/juris/document/document.jsf?text=\&docid=160007\&pagelndex=0\&doclang=ES\&mode =req\&dir=\&occ=first\&part=1\&cid=290199 , [Consulta: 13/11/2016].

El próximo día de Europa (9 de mayo de 2017) prevé presentar ante el Parlamento un Documento firmado por profesionales del derecho, de la política y de la sanidad, encaminado dar visibilidad a sus reivindicaciones y a poner de manifiesto la conveniencia de que la iniciativa pueda debatirse en el parlamento, vid., https://www.oneofusappeal.eu/es/ [Consulta: 13/11/2016].

28 BGH, Urteil vom 27. November 2012-X ZR 58/07, Bundespatentgericht. Disponible en http://juris.bundesgerichtshof.de/cgibin/rechtsprechung/document.pyGericht=bgh\&Art=pm\&Datum=2012\&So $\mathrm{rt}=3 \& a n z=197 \&$ pos $=0 \& \mathrm{nr}=62892 \&$ linked=urt\&Blank=1\&file=dokument.pdf De ella me ocupé en el trabajo "Embriones no viables, ¿embriones patentables? Comentario a la sentencia del Bundesgerichtshof, de 27 de noviembre de 2012, en el asunto Brüstle v. Greenpeace", Diario La Ley, No 8084, Sección Doctrina, 16 May. 2013, Año XXXIV., vid., SERRANO RUIZ CALDERÓN, J.M., Precisión en el concepto de embrión humano a efectos del derecho de patentes. La exclusión del partenote", La Ley Unión Europea, número 27, 2015, p. 2.

${ }^{29}$ Para fundamentar su tesis de que cabe obtener células madre de embriones sin destruirlos, el Tribunal nos remite a dos artículos científicos, presentados como prueba por la defensa y literalmente citados en la sentencia (pruebas E8 y E9). Ambos se refieren a procedimientos de obtención de células madre a partir de embriones no viables. GAVRILOV, PROSSER et al, «Non-viable human embryos as a source of viable cells for embryonic stem cell derivation», Reprod Biomed Online 18 Februar 2009, S. pp. 301 ff., GAVRILOV, MARLOT et al, "Derivation of Two New Human Embryonic Stem Cell Lines from Nonviable Human Embryos", Stem Cells International, Vol 2011, Article ID 765378.

Una vez considerado que el actual estado del arte permite la obtención de células pluripotentes sin destrucción de embriones, el Tribunal entiende que es suficiente la inclusión de la cláusula "sin destrucción de embriones" en la información técnica de la patente para entender probado que se ha empleado alguno de estos procedimientos no destructivos. Vid., Sentencia de BGH, cit., parágrafo 35. 
El Bundesgerichtshof entiende que un embrión no viable, a pesar de ser un embrión fecundado, no entra dentro de este concepto de embrión, ya que su no viabilidad implica su imposibilidad de dar lugar al desarrollo de un ser humano.

Desde mi punto de vista, la interpretación del tribunal alemán no se ajusta al espíritu de "amplitud" que, en nombre de la dignidad humana, presidía la determinación del concepto realizada por el TJUE. Además, y aunque no se hace explícito en la sentencia del caso Brüstle, de las Conclusiones de Bot sí cabe extraer la conclusión de que el criterio para determinar cuándo estamos ante un embrión no tiene que ver con su posibilidad fáctica de sobrevivir hasta convertirse en un ser humano, sino, más bien, con la idea de totipotencialidad ${ }^{30}$. Pues bien, si interpretamos la doctrina Brüstle en el sentido de vincular el concepto de embrión a la totipotencialidad, entonces, la patente sólo sería admisible si la obtención de la célula no causa la destrucción del embrión (pues los no viables serían embriones). Si, en cambio, entendemos que para ser considerado embrión se ha de tener la posibilidad de finalizar ese proceso de desarrollo que da lugar a un ser humano, entonces los embriones no viables serían, según Brüstle, embriones patentables.

La OEP ha entendido que el proceso que Brüstle pretende patentar sí implica la destrucción de embriones. En su decisión de febrero de $2015^{31}$, la OEP confirma la revocación de la patente concedida a Brüstle y, en consecuencia, deniega la solicitud del neurobiólogo.

El proceso ante la OEP había empezado en 2006, cuando la empresa Geron denuncia la patente europea concedida a Brüstle. Geron era en aquel momento la titular en Estados Unidos de la patente WARF $^{32}$, que autorizaba la investigación con células madre de origen embrionario. Dicha patente fue rechazada por la OEP en $2008^{33}$, al estimarse que se trataba de una investigación contraria al orden público, por implicar la destrucción de embriones humanos (entendiendo la noción de orden público conectada a la prohibición expresa de patentar embriones de la Directiva 44/98) ${ }^{34}$.

Geron recurre la concesión de la patente, que es revocada por la OEP a resultas del proceso en $2013^{35}$. Esa decisión es, a su vez, recurrida por la asistencia letrada de Brüstle, pero la Cámara de Recursos de la OEP solo estimó devolver a la primera

\footnotetext{
${ }^{30}$ Esta tesis se confirma en la sentencia del caso ISCO, como veremos a continuación.

${ }^{31}$ Decision of the Board of Appeal, 18-06-2015, Todos los documentos del proceso Geron c. Brüstle ante la OEP pueden descargarse en https://register.epo.org/application?number=EP98966817\&tab=doclist [Consulta: 10/11/2012]

${ }^{32}$ Sobre la patente WARF en Estados Unidos, vid., entre otros, LAFERRIERE, N., Cuestiones jurídicas en torno a la patentabilidad de las invenciones que involucran embriones humanos, Instituto de Bioética, Buenos Aires, 2013, http://www.ancmyp.org.ar/user/files/Laferriere13.pdf [Consulta: 10/11/2016]; Sobre su significación en Europa y su relación con la sentencia Brüstle, vid., GARCIA SAN JOSÉ, D., "Derecho de la Unión, investigación embrionaria humana y patentes biológicas", Revista de Derecho Comunitario europeo, 41, 2012, pp. 161-180, donde se considera un error la extensión de la ratio decidendi del caso WARF al caso Brüstle.

${ }^{33}$ Caso G 0002/06, T 1374/04 (Stammzellen/WARF) de 7.4.2006; Decisión de 25 de noviembre de 2008, Disponible en http://www.epo.org/law-practice/case-law-appeals/recent/t041374dp1.htm|\#qwarf,

${ }^{34}$ Idem., Q. 2., parágrafo 31.

35 Geron retira su oposición a la demanda en 2014 . Vid., https://register.epo.org/application?number=EP98966817\&tab=doclist; Withdrawal of an opposition, 28.03.2014., tras abandonar la investigación con células madre de origen embrionario, como veremos más adelante.
} 
instancia para su examen la patente en la forma solicitada en la petición subsidiaria 6모 (en que se excluye el empleo de células madre de origen embrionario humano ${ }^{36}$. El asunto está pendiente de la vista que se celebrará el día 19 de diciembre de $2016^{37}$.

\section{LA JURISPRUDENCIA POST-BRÜSTLE DEL TJUE: EL CASO ISCO ¿QUÉ ES UN ORGANISMO APTO PARA INICIAR EL PROCESO DE DESARROLLO DE UN SER HUMANO?}

El 18 de diciembre de 2014 el TJUE resolvía otra cuestión prejudicial relativa al concepto de embrión humano en la Directiva de Patentes. Esta vez, la cuestión había sido planteada por la High Court of Justice de Reino Unido en abril de 2013, en el asunto entre International Stem Cell Corporation (ISCO) y el Comptroller General of Patents, Designs and Trade Marks. Esta vez, la cuestión prejudicial es más sencilla, y se refiere explícitamente a los embriones partenogénicos: “¿Están comprendidos en la expresión "embriones humanos" contenida en el artículo 6, apartado 2, letra c), de la Directiva $98 / 44[\ldots]$, los óvulos humanos no fecundados que han sido estimulados mediante partenogénesis para que se dividan y sigan desarrollándose y que, a diferencia de los óvulos fecundados, sólo contienen células pluripotentes y no son aptos para convertirse en seres humanos?»

Como cabe observar, el asunto se circunscribe a los embriones partenogénicos (en adelante, partenotes), y la reinvindicación de la parte consiste en afirmar que, en aplicación de la propia doctrina Brüstle, los partenotes no serían realmente embriones humanos, ya que ni contienen células totipotentes ni son aptos para convertirse en seres humanos.

El abogado general, Cruz Villalón, atiende en sus Conclusiones ${ }^{39}$ la práctica totalidad de las alegaciones de ISCO. Justifica la inclusión de los partenotes en el concepto de embrión de la sentencia Brüstle en el hecho de que según las observaciones

36 Añadiendo la cláusula "mit Ausnahme des Menschen" (Hilfsantrag 6"). https://register.epo.org/application?number=EP98966817\&tab=doclist;26.01.2015, Claims. La OEP es aquí coherente, no sólo con la decisión del caso WARF y con su propia decisión sobre este asunto en 2013, sino también con la decisión en el caso T-2221/10, de 4 de febrero de 2014 (Cámara de Recursos) en la que se deniega la patente sobre la base de que las líneas celulares se obtuvieron mediante destrucción de embriones. Vid., VIDAL GARCÍA, A., "La patentabilidad de las células madre embrionarias: decisión de la Cámara de Recursos de la Oficina Europea de Patentes de 4 de febrero de 2014 (caso T- 2221/10)", Análisis Farmacéutico GA\&P, marzo 2014, http://www.gomezacebo-pombo.com/media/k2/attachments/lapatentabilidad-de-las-celulas-madre-embrionarias-decision-de-la-camara-de-recursos-de-la-oficina-europeade-patentes-de-4-de-febrero-de-2014-caso-t-2221-10.pdf [Consulta: 10/11/2016].

37 Sentencia del Tribunal de Justicia (Gran Sala), de 18 de diciembre de 2014,en el asunto C-364/13. Disponible en http://curia.europa.eu/juris/liste.jsf?num=C-364/13 [Consulta 10/11/2016]. Se trataba de dos solicitudes de patentes, la primera reivindicaba procedimientos de producción de líneas de células madre humanas pluripotentes a partir de ovocitos activados mediante partenogénesis; la segunda, procedimientos de producción de córnea sintética o tejido de la córnea consistentes en aislar células madre pluripotentes a partir de ovocitos activados mediante partenogénesis, así como la córnea sintética o tejido de la córnea producido con arreglo a dichos procedimientos.

${ }^{38}$ Sentencia C-364/13, cit., parágrafo 20.

39 "Conclusiones" del Abogado General Cruz Villalón, presentadas el 17 de julio de 2014. Disponible en http://curia.europa.eu/juris/liste.jsf?num=C-364/13 [Consulta 10/11/2016]. 
escritas presentadas al Tribunal" se podrían obtener de ellos células totipotentes ${ }^{40}$. Al establecerse científicamente que esto es imposible, pues los partenotes, debido a la impronta genética, no pueden en ningún caso dar lugar a la generación de un ser humano y no superan la fase de blastocisto, ha de entenderse que, de conformidad con la doctrina Brüstle, los partenotes no deben considerarse embriones. El requisito de "apto para iniciar el desarrollo de un ser humano" ha de entenderse como la posesión de la capacidad "intrínseca" ${ }^{41}$ para iniciar ese desarrollo, lo que no ocurre en el caso de los partenotes.

La sentencia acoge las Conclusiones y falla a favor de ISCO. Desde mi punto de vista, la sentencia del caso ISCO no altera en lo fundamental la doctrina Brüstle, sino que simplemente corrige un error de "calificación": el partenote no es, conforme a los criterios establecidos en Brüstle, un embrión humano, porque "no dispone, como tal, de la capacidad intrínseca para convertirse en un ser humano" ${ }^{\text {. }}$.

\section{CUESTIONES PENDIENTES EN TORNO A LA DOCTRINA BRÜSTLE: ¿QUÉ ES UN ORGANISMO INTRÍNSECAMENTE APTO PARA DAR LUGAR AL DESARROLLO DE UN SER HUMANO?}

\section{a. Un nuevo escenario para la investigación con células madre de origen embrionario}

Tras la sentencia del asunto Brüstle, al final de 2011, la empresa Geron, titular de la patente WARF y recurrente ante la OEP en el caso de la patente europea Brüstle, decidió cancelar el primer ensayo clínico en el que se empleaban células pluripotenciales de embriones humanos con la finalidad de buscar un remedio a las lesiones medulares, anunciando que a partir de ese momento centraría sus esfuerzos en la investigación con células madre adultas ${ }^{43}$. No es difícil calibrar la relevancia de esta retirada y su significación para la investigación científica en el campo de las células progenitoras ${ }^{44}$.

\footnotetext{
40 "Conclusiones" del Abogado General Cruz Villalón, cit., parágrafo 72.

${ }^{41}$ Idem., parágrafo 74 .

${ }^{42}$ Sentencia C-364/13, cit., parágrafo 39. Subrayado añadido.

${ }^{43}$ Era la primera vez que una investigación entraba en la fase de experimentación con personas, y los primeros candidatos ya habían sido seleccionados. En el comunicado de prensa, Geron adujo razones de carácter económico para explicar el giro en su política. Vid., la información sobre el impacto de la decisión de Geron en http://abcnews.go.com/Health/Wellness/scientists-rethink-embryonic-stem-cell-research-geronannouncement/story?id=14966735 [Consulta: 14/11/2016]
}

${ }^{44} \mathrm{Si}$ atendemos a los proyectos que por el momento han obtenido financiación en el marco de H2020, el porcentaje de los que emplean en su investigación células madre de origen embrionario no es todo lo relevante que cabría esperar, sobre todo considerado en relación a las dimensiones de la polémica en torno a si este tipo de proyectos debían o no ser financiados. En Cordis se encuentran registrados actualmente 9056 proyectos de investigación financiados en el marco de H2020 (disponible en https://data.europa.eu/euodp/es/data/dataset?q=cordis\&ext boolean=all\&sort=views total+desc). El

\begin{tabular}{llllll}
\hline presupuesto total & de & $\mathrm{H} 2020$ & es & de & 77.028M€
\end{tabular} (http://www.cdti.es/recursos/doc/5811 10111011201320716.pdf). Una búsqueda en la base de datos de proyectos concedidos de los ítems "human embryonic stem cells" y "hu-ES" en la información resumida de la memoria de los proyectos (salvo error u omisión por mi parte) da como resultado tres investigaciones: ERC StG-2015, "Mediation of stem cell identity and aging by proteostasis" (1.500.000€); PHC-15-2015 "Betacell Generation by stem cell-derived implents in diabeties" (6.200.000€); MSCA-IF-2015-EF "Understanding celular mechanism of human brain development using cerebral organoides" $(166.156,8 €)$, que representan una inversión total de 7.866.156,8€, que equivaldría a un $0,01 \%$ del presupuesto total de H2020 (ha de tenerse en cuenta que el programa está aún abierto y que el porcentaje calculado lo es sobre el total de financiación disponible). 
En lo que respecta a la comercialización de esta investigación, hemos de tener presente que el propio sistema de patentes europeo está en espera de una importante modificación ${ }^{45}$. El nuevo "paquete de patentes" de la UE supone la creación de una "patente unitaria" que tendrá efecto directo en todos los países de la Unión (excepto, de momento, en España e Italia), y la puesta en marcha de un Tribunal Unificado de Patentes encargado de la fiscalización de esta patente europea ${ }^{46}$.

Este nuevo escenario parece mostrar dos cosas: que la comunidad científica parece, al menos por el momento, inclinarse por la investigación con células madre de origen no embrionario ${ }^{47}$, y que vamos camino de un sistema de patentabilidad aún más estructurado en el marco de la UE, con una patente unitaria válida en toda la Unión y sometida con carácter directo, en tanto institución comunitaria, a la jurisprudencia del TJUE, y, por tanto, a la doctrina Brüstle, sin posibilidad de interferencia de los tribunales nacionales.

Desde mi punto de vista, dentro de este futuro escenario, las instituciones de la UE deberán abordar al menos dos cuestiones. La primera, de la que me ocupo a continuación, es de carácter material y tiene que ver con el problema de los embriones no viables y su estatuto jurídico. La segunda es de carácter formal y, aunque excede los límites de este trabajo, no podemos dejar de mencionarla: se trata del cómo se determina qué es un embrión humano. En este debate, como se ha podido comprobar, hay muchas voces relevantes y todas ellas pueden legítimamente esperar que se les permita tomar parte en la decisión. La cuestión requiere, en mi opinión, un ejercicio de democracia deliberativa ${ }^{48}$, y lo que sigue ha de entenderse como nuestra contribución a este debate.

\begin{abstract}
${ }^{45}$ El tratado en virtud del cual entrará en vigor el nuevo paquete europeo de Patentes está en proceso de ratificación. Se esperaba su aprobación inminente, al principio de 2017. Pero tras el referéndum en Reino Unido, la situación post-Brexit es difícil de prever, puesto que la entrada en vigor del acuerdo exige la ratificación de Francia, Alemania y Gran Bretaña (actualmente, la ratificación de estos más un Estado adicional sería suficiente para su entrada en vigor. Vid., SANCHEZ-PUELLES, C., EI IP BREXIT y la Patente Europea con Efecto Unitario y el Tribunal Unificado de Patentes, 8 de julio de 2016, http://www.clarkemodet.com/es/actualidad/blog/2016/07/el-ip-brexit-y-la-patente-europea-con-efectounitario-y-el-tribunal-unificado-de-patentes.html\#.WCse0GU7XR0 [Consulta: 14/11/2016]

${ }^{46}$ El nuevo Tribunal convivirá con la OEP. La OEP no es una institución de la UE (está vinculada a la Convención europea de Patentes), de hecho, a la OEP pertenecen una serie de países que no son miembros de la UE. No obstante, como hemos visto, ambas instituciones (OEP y TJUE) están perfectamente alineadas en las decisiones más importantes. "If the judges rule in favour of a restrictive interpretation of biotech patentability provisions, the EPO will immediately implement it", (declaraciones a propósito de la sentencia del caso Brüstle del Presidente de la OEP) BATTISTELLI, B., "Patents and biotechnology - latest developments", http://blog.epo.org/patents/patents-and-biotechnology---latestdevelopments/, epoblog [Consulta: 13/11/2016].
\end{abstract}

${ }^{47}$ No es preciso subrayar la importancia de que las soluciones propuestas por los juristas tengan presente las opiniones dominantes en la comunidad científica y no se construyan de espaldas a los estándares de ética profesional de la propia comunidad. De hecho, una comunidad científica firmemente convencida de las bondades de la investigación con células madre de origen embrionario encontraría las fórmulas para proteger en el mercado estas invenciones sin necesidad de recurrir a la patente (por ejemplo, a través de la regulación del secreto profesional), con lo que el derecho devendría ineficaz como instrumento de regulación de este ámbito del mercado, vid., HARMON, S.H.E., GRAEME, L., "Dignity, plurality and patentability: the unfinished story of Brustle v Greenpeace", European Law Review, 2013, pp. 1-13, p. 9. PLOMER, A., "Case C-364/13-Patentability of Embryonic Stem Cells and Parthenotes: Inherently Uncertain?", EUtopia Law, 19, December 2014, pp. 134 y ss. FIELD, J., The Patentability of Human Embryonic Stem Cell-Based Inventions in the European Union, Aberdeen Student Law Review 2015, Volume 6, p. 6.

${ }^{48}$ SIDERI, K., Bioproperty, Biomedicine and Deliberative Governance: Patents as discurse of live, Routledge, New York, 2016. 
b. Los embriones supernumerarios no viables, ¿son embriones?

Queda pendiente aún determinar cuál es la interpretación correcta de la doctrina Brüstle en su aplicación al caso de los embriones supernumerarios inviables. Ya hemos visto que el Bundesgerichtshof entendió que los procedimientos de obtención de células pluripotentes a partir de embriones no viables son patentables porque no suponen la destrucción de embriones.

La propia ISCO recurre a la sentencia del Bundesgerichtshof como argumento en defensa de la patentabilidad de los partenotes: "el Tribunal alemán consideró que determinados organismos no viables desarrollados a partir de ovocitos fecundados mediante fecundación in vitro no son embriones con arreglo a lo declarado por el Tribunal de Justicia, por cuanto no son capaces de desencadenar el proceso de desarrollo de un ser humano" ${ }^{\prime 9}$. La tesis que defiendo a continuación es que las razones por las cuales no son viables no son irrelevantes a la hora de determinar su régimen jurídico.

El nuevo escenario de patentes europeas exige hoy un criterio europeo común para responder a la pregunta ¿qué es un embrión humano?, o dicho de otra manera, ¿cómo debemos interpretar la expresión "intrínsecamente apto para iniciar el proceso de desarrollo de un ser humano"? A mi juicio, debería considerarse como criterio determinante el concepto de totipotencialidad. Un organismo es un embrión humano cuando sus células son, o han sido en fases previas de su desarrollo, totipotentes ${ }^{50}$. Conforme a este criterio, los partenotes no serían embriones humanos, pero los embriones no viables sí, de modo que si el procedimiento para obtener células pluripotentes a partir de ellos da lugar a su destrucción, esa invención no sería patentable en el ámbito europeo.

En mi opinión, cuatro razones sostienen esta opción. Primero, el tratarse de un criterio relativamente más cierto que el de viabilidad, que es de más difícil definición y menos adecuado para ser empleado como criterio jurídico.

Segundo, por corresponderse más adecuadamente con la amplitud que, en nombre del respeto a la dignidad humana, el TJUE ha exigido en la noción de embrión, primero en Brüstle y, años después, en el caso ISCO. Es importante hacer constar aquí que esta es también la línea marcada por el Tribunal Europeo de Derechos Humanos. Así, en Vo c. Francia, se parte de la pertenencia del embrión a la especie humana como algo consensuado en los Estados miembros, y se afirma que su capacidad para convertirse en una persona requiere la protección del derecho en nombre de la dignidad humana, sin que esto suponga convertirlo en una "persona" a los efectos del artículo 2 (reconocimiento del derecho a la vida) ${ }^{51}$.

\footnotetext{
49 "Conclusiones" del Abogado General Cruz Villalón, cit., parágrafo 58.

${ }^{50}$ Del mismo modo, siguiendo la argumentación de Bot, una sola célula totipotente sería un embrión humano, mientras que no lo sería, en el actual estado de la ciencia, una célula pluripotente, ya que ésta última no puede generar un individuo de la especie humana.

51 "At best, it may be regarded as common ground between States that the embryo/foetus belongs to the human race. The potentiality of that being and its capacity to become a person - enjoying protection under the civil law, moreover, in many States, such as France, in the context of inheritance and gifts, require protection in the name of human dignity, without making it a "person" with the "right to life" for the purposes of Article 2". STEDH Vo c. Francia, cit., parágrafo 84. A pesar de ello, parte de la doctrina sostiene que la doctrina Brüstle ignora la jurisprudencia del TEDH, vid., PLOMER, A., "After Brüstle: EU Accession to the ECHR and the Future of European Patent Law" (2012) 2(2) QMJIP, 110, pp. 123-124.
} 
Tercero, porque las mismas razones que avalan la naturaleza no embrionaria del partenote justifican la inclusión del embrión no viable de facto dentro de la categoría de embriones. Cuando la sentencia ISCO se refiere a una capacidad "intrínseca" de desarrollarse per se hasta dar lugar a un ser humano, nos está dando razones para entender que los embriones no viables son embriones, ya que su imposibilidad fáctica de convertirse en un ser humano no obedece a una carencia de potencialidad intrínseca de desarrollarse completamente, sino a una actividad humana, extrínseca al propio embrión, que es congelado, descongelado, activado hasta que alcanza la fase de blastocisto y después destruido ${ }^{52}$.

Cuarto, porque el empleo de este criterio de totipotencialidad impediría también la patente de los embriones clónicos, mientras que el criterio de la viabilidad daría luz verde a la patente de una actividad prohibida por la mayoría de las legislaciones nacionales de los países de la UE, la creación de embriones clónicos con fines de investigación ${ }^{53}$.

\section{CONCLUSIONES}

1. La doctrina Brüstle sigue planteando interrogantes en torno a la determinación de qué es hoy un embrión humano (a los efectos de la concesión de patentes). La principal cuestión gira en torno a la interpretación de la expresión "intrínsecamente apto para iniciar el desarrollo de un ser humano", debido a que esta expresión se ha interpretado en dos sentidos distintos: como una exigencia de "viabilidad" y como una exigencia de "totipotencialidad".

2. Estos interrogantes deben tratar de resolverse en todo caso, pero especialmente pensando en una futura patente unitaria europea.

3. Para hacerlo, sería deseable que se abriera un proceso de democracia deliberativa en el seno de las instituciones comunitarias, en el que todos los sujetos implicados pudieran participar.

4. La contribución de este trabajo a ese debate consiste en afirmar razonadamente que la doctrina Brüstle ha de interpretarse optando por la totipotencialidad frente a la viabilidad como concepto clave en la determinación de lo que es un embrión humano.

\footnotetext{
${ }^{52}$ Con todas las dificultades inherentes concepto de destrucción del embrión en el caso de estos embriones que no están "muertos", si bien no son viables y en este estado son activados hasta la fase de blastocisto y posteriormente destruidos durante el proceso de obtención de células. ¿Es susceptible de destrucción un organismo no viable? Creo que esta cuestión debe abordarse desde la misma perspectiva garantista que justifica el concepto "amplio" de embrión exigido por la dignidad humana ex sentencias Brüstle e ISCO.

${ }^{53}$ Para una diversa consideración del embrión denominado "somático", Vid., GARCíA SAN JOSE, D., op. cit., pp. 176-177.
} 


\section{BIBLIOGRAFÍA CITADA}

ALBERT, M., "El caso Brüstle v. Greepeace y el final de la discriminación de los embriones preimplantatorios", Cuadernos de Bioética, XXIV 2013/3ㄹ.

ALBERT, M., "Embriones no viables, ¿embriones patentables? Comentario a la sentencia del Bundesgerichtshof, de 27 de noviembre de 2012, en el asunto Brüstle v. Greenpeace", Diario La Ley, No 8084, Sección Doctrina, 16 May. 2013, Año XXXIV.

ABBOTT, A., Nature 471, 2011, "Europe rules against stem-cell patents", 16 de marzo de 2011,

CASINI, C., CASINI, M., SPAGNOLO, A., "La sentenza della Corte di giustizia dell'Unione europea del 18 ottobre 2011 e la nozione di embrione in senso ampio", en Medicina e Morale, 2011-5.

DENOON, A., "Brüstle v. Greenpeace: implications for stem cell research", en Intelllectual Property, Regenerative Medicin, 2011, 6.

FIELD, J.,The Patentability of Human Embryonic Stem Cell-Based Inventions in the European Union, Aberdeen Student Law Review 2015, 6.

GARCÍA SAN JOSÉ, D., "Derecho de la Unión, investigación embrionaria humana y patentes biológicas", Revista de Derecho Comunitario europeo, 41, 2012

GAVRILOV, PROSSER et al, «Non-viable human embryos as a source of viable cells for embryonic stem cell derivation», Reprod Biomed Online 18 Februar 2009.

GAVRILOV, MARLOT et al, "Derivation of Two New Human Embryonic Stem Cell Lines from Nonviable Human Embryos", Stem Cells International, Vol 2011.

HARMON, S.H.E., GRAEME, L., "Dignity, plurality and patentability: the unfinished story of Brustle v Greenpeace", European Law Review, 2013.

LACADENA, JR., "Sentencia del Tribunal de Justicia de la Unión Europea sobre las patentes de células troncales embrionarias. A propósito de un informe jurídico sobre patentes: El concepto y dignidad del embrión humano", en Revista de Derecho y Genoma Humano, 35:pp.145-180 (2011).

LAFERRIERE, N., Cuestiones jurídicas en torno a la patentabilidad de las invenciones que involucran embriones humanos, Instituto de Bioética, Buenos Aires, 2013.

JONES, D. A., "More at stake in stem-cell patents" Nature 474, 30 June 2011.

PLOMER, A., "After Brüstle: EU Accession to the ECHR and the Future of European Patent Law" (2012) 2(2) QMJIP, 110.

PLOMER, A., "Case C-364/13-Patentability of Embryonic Stem Cells and Parthenotes: Inherently Uncertain?", EUtopia Law, 19, December 2014.

SANCHEZ-PUELLES, C., EI IP BREXIT y la Patente Europea con Efecto Unitario y el Tribunal Unificado de Patentes, 8 de julio de 2016 (publicación en línea: http://www.clarkemodet.com/es/actualidad/blog/2016/07/el-ip-brexit-y-la-patente-europea-con-efectounitario-y-el-tribunal-unificado-de-patentes.html\#.WCueemU7XR1).

SERRANO RUIZ-CALDERÓN, JM., Dignidad versus patentabilidad (Comentario de la STJ 18 de octubre de 2011 en el asunto Brüstle/ Greenpeace), en LA LEY, No 7766, Sección Tribuna, 30 Dic. 2011, Año XXXII.

SERRANO RUIZ CALDERÓN, J.M., "Precisión en el concepto de embrión humano a efectos del derecho de patentes. La exclusión del partenote", La Ley Unión Europea, número 27, 2015.

SIDERI, K., Bioproperty, Biomedicine and Deliberative Governance: Patents as discurse of live, Routledge, New York, 2016.

SMITH, A., 'No' to ban on stem-cell patents", Nature, 472, 28 April 2011.

VIDAL GARCíA, A., "La patentabilidad de las células madre embrionarias: decisión de la Cámara de Recursos de la Oficina Europea de Patentes de 4 de febrero de 2014 (caso T- 2221/10)", Análisis Farmacéutico GA\&P, marzo 2014. 